\title{
Introduction Part 2 - Asia Present and Resonant: Themes of Connectivity and World-making in Contemporary Asian Art
}

\author{
Michelle Antoinette
}

The essays in this book provide new ways of understanding Asia and its art as sites not only of local cultural difference, but also regional and worldly connection-connections between Asia and the world, inter-Asia or intraAsian regional connections, empathic connections forged via art's affective and sensory possibilities, and Asia-Australia connections. With its art focus, the authors engage with these four key themes to investigate what Asian art reveals about such cultural connections and examine how these issues are particular to Asia. In so doing the essays emphasise the connective medium of art itself as a vital key in forging connection for the region and between the region and the world. Art is also revealed as a means of conveying other perspectives on the world based on Asian affinities and experiences, but also for the imagination and generation of new ways of being and belonging in the world at large.

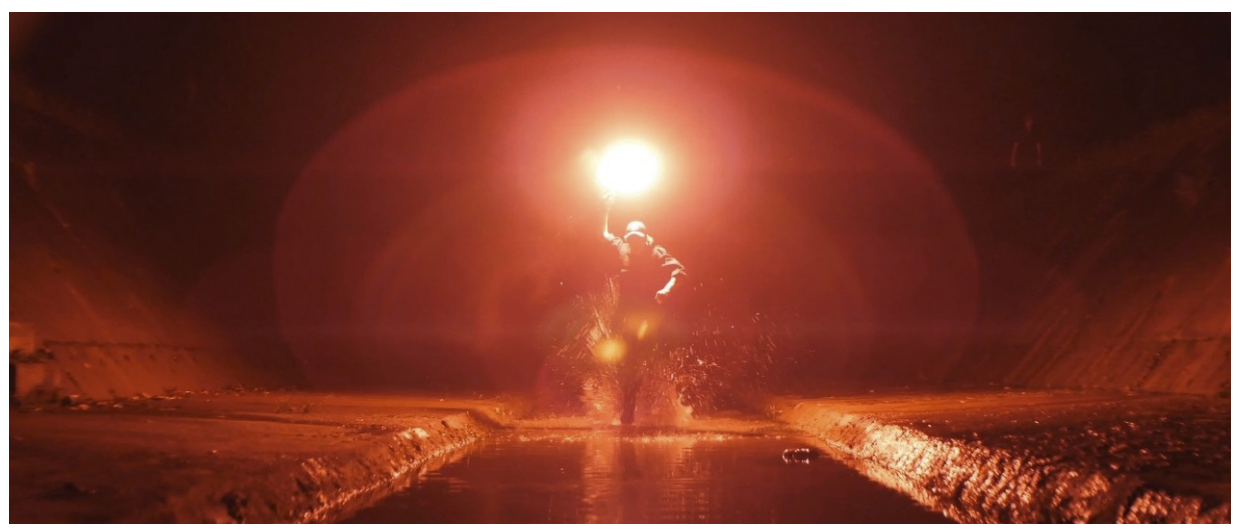

Charles Lim, all lines flow out 2011 (video still); video installation; 21 min.

Image courtesy the artist

Together, the essays examine the field of Asian art both as a site of cultural connectedness and a platform for generating cultural connectivities. They trace the multiple lines of historical and contemporary connectedness that mark Asia and which have influenced the shape of its modern and contemporary 
art landscape. In this, Asia itself is not a homogenous landscape, but a site of multiple and intersecting geographies, cultures, societies, histories and landscapes - within. Asia is thus already posited as a site of interconnection, the historical consequence of intra-regional crossings, but also, the historical effect of intersecting local and global influences.

In Part 1 of this introduction to the volume, Caroline Turner discusses the changing contexts for Asian art in a transforming world. Following Turner's mapping of contemporary Asian art's contexts, I provide here an outline of the individual essays in this volume, and more closely examine their themes of 'connectivity' and 'world-making'. The attention being given to contemporary Asian art, as Turner notes, has brought to light the predominance of 'Western' world views in the history of modern and contemporary art. Indeed, in the context of continuing debates regarding the definition and constitution of 'the modern' and 'the contemporary', the essays in this volume reveal the EuroAmerican bias of modern art history and demonstrate the specificity and vitality of Asian art and exhibition.

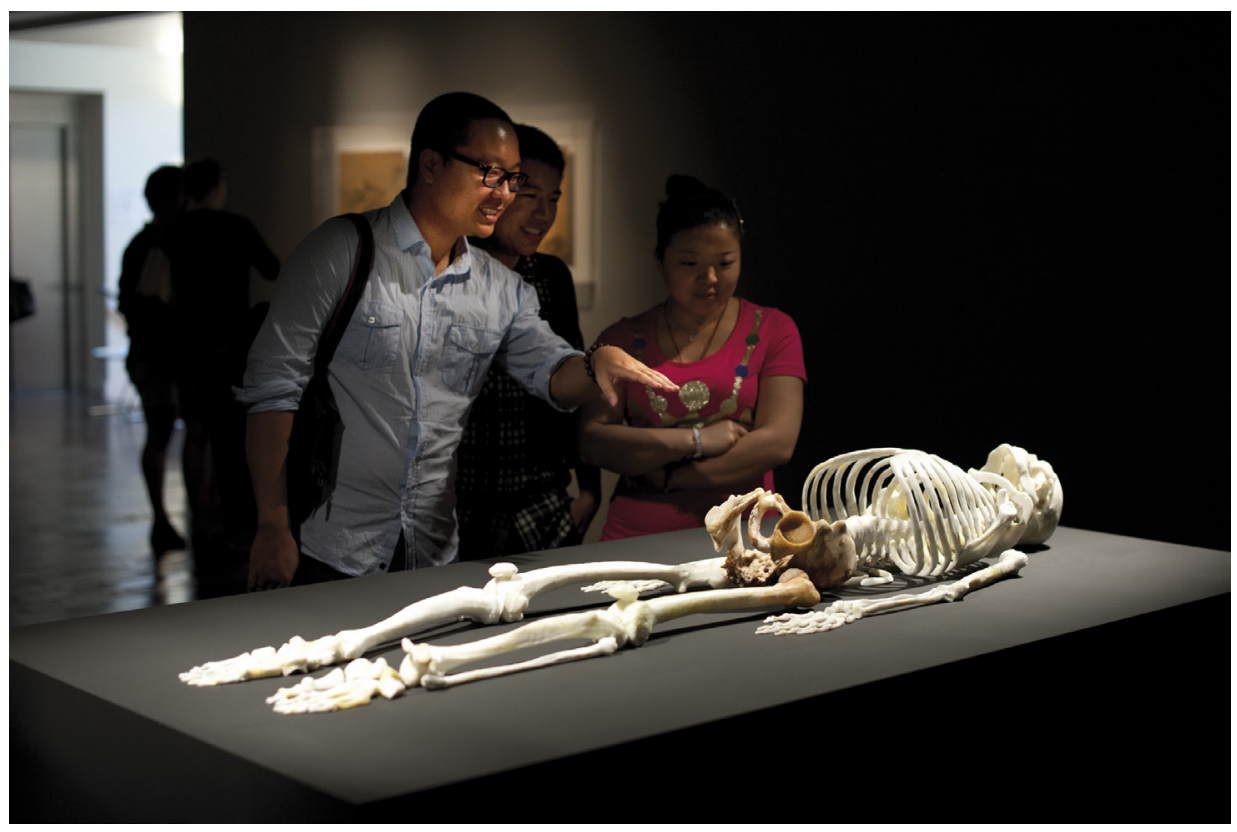

He Xiangyu, Cola Project 2012; installation view at 4A Centre for Contemporary Asian Art.

Courtesy the artist and White Space, Beijing; photograph: Garry Trinh 


\section{Tracing Connectedness | Connective Proposals}

The essays gathered in this book coalesce around four key themes or modes of 'connectedness' and 'connectivity', which we have identified as important threads across the essays in their attention to modern and contemporary Asian art and exhibitions. The co-relation of these key themes may be read as the multidisciplinary intersection of art history, Asian studies and cultural studies - a conjoining of areas that is provoked by the demands of understanding the interdisciplinarity and cross-cultural intersections of modern and contemporary Asian art itself. This issue, of questioning conventional disciplinary approaches to Asian art founded in Euro-American experience, is at the heart of worldwide debates on the meaning of 'contemporary art', as divergent art forms from diverse locales come into dialogue in world contexts-for example, via international exhibitions. In Asia, as cultural institutions are established to meet the burgeoning interest in cultural industries, the issue of Asian art's culturally and aesthetically 'appropriate' representation has become acute, as seen, for instance, in debates over the $\mathrm{M}+$ museum project in Hong Kong (see Ho, this volume) with its competing narratives of visual culture, popular culture, globalised 'contemporary art', and local 'Hong Kong' and 'Chinese' creative histories.

Part of the motivation for gathering this diverse collection of essays is to highlight and draw attention to the range of connectivities that may be mapped in relation to Asian art. Several essays fit more than one theme and demonstrate that the kinds of projects for which Asian art is put to 'connective' tasks are many and varied. This includes art historiography (Clark, Flores, Turner, Antoinette), art exhibitions (Sambrani, Ho, Hoffie, Carroll, Turner), cultural diplomacy and exchange projects (Turner, Carroll), community and participatory engagements (Ho, Maravillas, Antoinette), forging national and world imaginaries (Clark, Flores, Turner, Meskimmon), commercial exchanges and transactions (Antoinette, Clark), intra-regional exploration and affinities (Merewether, Hoffie, Sambrani, Turner, Antoinette), eliciting empathy and provoking responsibility (Flores, Meskimmon, Maravillas, Lo) and, at its most essential level, communicating with diverse audiences on contemporary issues (Hoffie, Merewether, Antoinette), especially via the fundamental sensory and affective encounter with art (Meskimmon, Maravillas). 


\section{World-making and Making Worlds}

Our volume's first theme of 'world-making'1 not only offers a lens onto the mapping of Asia in the world-especially of Asia within the world's art histories - but also the figuration of Asia and Asian art as sites and agencies of 'worlding' and 'world-making'. Through such processes Asia is registered as an alternative viewpoint from which to imagine and make real Asia-specific visions of the world that are different from the hegemonic and undifferentiated universalisms of the West. In this way, Asia is repositioned as a critical agency and agent for 'reworlding' our perspectives, ${ }^{2}$ allowing us to imagine the world from the position of locales that were previously overshadowed by Euro-American hegemonic universalisms, to recognise Asia and Asian art in the world, and to construct a space for Asian perspectives within world imaginaries.

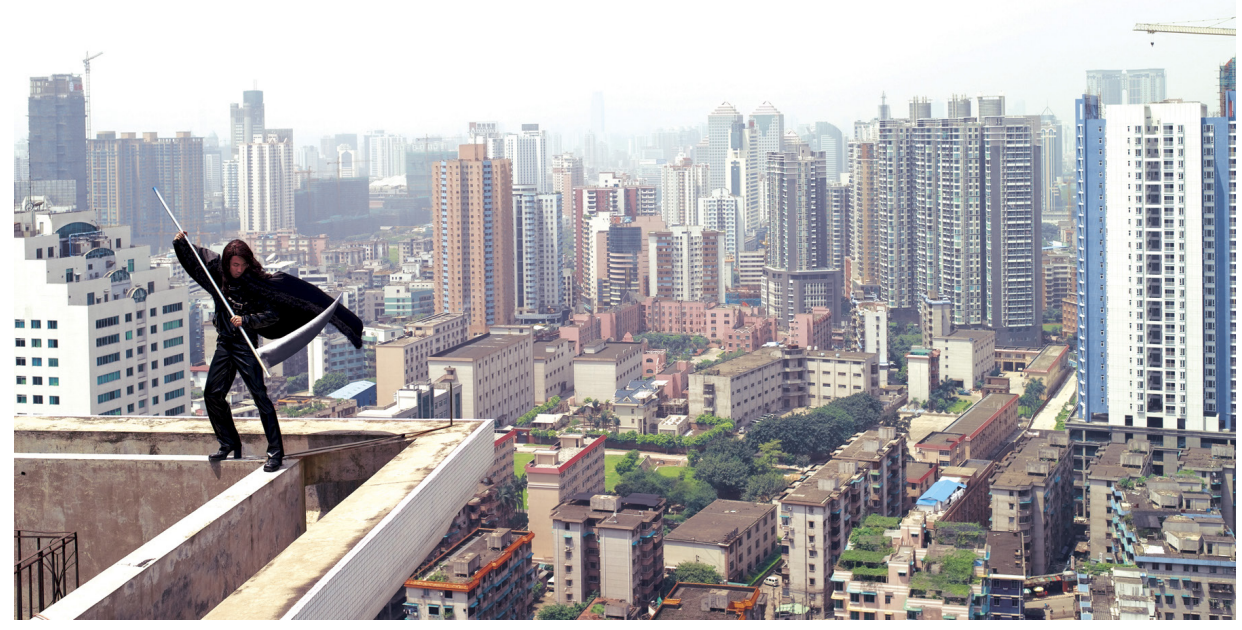

Cao Fei, City Watcher from the Cosplayers series 2004; photo; $100 \times 70 \mathrm{~cm}$.

Courtesy the artist and Vitamin Creative Space 2013

\footnotetext{
1 See Caroline Turner, Michelle Antoinette \& Zara Stanhope eds, The World and World-Making in Art, special issue, Humanities Research 19, no. 2 (2013).http://press.anu.edu.au/titles/humanities-research-journalseries/volume-xix-no-2-2013; Zara Stanhope \& Michelle Antoinette, 'The World and World-Making in Art: Connectivities and Differences', World Art 2, no. 2 (2012): 167-71.

2 Michelle Antoinette, Reworlding Art History: Encounters with Contemporary Southeast Asian Art after 1990 (Amsterdam \& New York: Rodopi, 2014).
} 
Significantly, there is a sense that the inherent worldliness of modern and contemporary art-its generation within a world context-emphasises connectedness and connectivity within and between diverse locales. Thus, the modern and contemporary art of Asia is simultaneously Asian and of the world and, following the contemporary art theory developed by art historian Terry Smith and noted by Turner in Part I of this Introduction, is 'from the world' and potentially 'for the world'. ${ }^{3}$ Essays in this volume by John Clark, Patrick Flores, Marsha Meskimmon, Francis Maravillas and Turner, in particular, draw our attention to this theme of worlding and world-making. In her essay, Turner discusses the geopolitical and Asia-centred contexts for a world-making and world-envisaging perspective in contemporary Asian art. Flores and Clark suggest Asia-based views of the world in history and their effect for present-day Asian art engagements in the world and with the world. By contrast, Meskimmon and Maravillas focus on the worlding processes and 'cosmopolitics' ${ }^{4}$ that are engendered in the artistic projects of selected contemporary Asian artists. ${ }^{5}$ The 'cosmopolitan imagination', as Meskimmon has argued elsewhere, is intimately tied not only to the new geographic crossings of contemporary artists in the world, but also to the cross-cultural communicative possibilities of their very art practice. In this sense, contemporary artists may actively create and offer alternative imaginations of the world, but also invite audiences themselves to reflect on and partake in drawing their own worlds, especially so as to map new connections with others in the world.

As Turner intimates in her essay, 'the contemporary' does not emerge from a vacuum but arises from specific histories of modern art development in Asia. With its historicising impetus, Clark's essay provides a retrospective examination of how we have arrived at the present conditions for contemporary Asian art. Clark maps a genealogy of sorts for recognising the specific connective trajectories and forms of what he calls the 'Asian Modern', a topic of long-standing interest to him. ${ }^{6} \mathrm{He}$ suggests that the beginnings of such modern worlding from Asian perspectives may be traced to a specific period: "Worlding", from the outset, meant making local interpretive frames visible in a global perspective across cultural and temporal zones because, from the early nineteenth century, there was the potential

\footnotetext{
3 Terry Smith, 'Currents of World-Making in Contemporary Art', World Art 1, no. 2 (2011): 175.

4 Pheang Cheah \& Bruce Robbins, eds, Cosmopolitics: Thinking and Feeling Beyond the Nation, Cultural Politics Series vol. 14 (Minneapolis \& London: University of Minnesota Press, 1998); Edwin Jurriëns \& Jeroen de Kloet, eds, Cosmopatriots: On Distant Belongings and Close Encounters (Amsterdam \& New York: Rodopi, 2007).

5 On cosmopolitan practices in contemporary art, see Marsha Meskimmon, Contemporary Art and the Cosmopolitan Imagination (London \& New York: Routledge, 2011); Nikos Papastergiadis, Cosmopolitanism and Culture (Cambridge \& Malden MA: Polity, 2012); Charlotte Bydler, The Global Art World, Inc.: On the Globalization of Contemporary Art (Uppsala: Acta Universitatis Upsaliensis, 2004).

6 John Clark, 'Open and Closed Discourses of Modernity in Asian Art', in Modernity in Asian Art, ed. John Clark (Sydney: Wild Peony, 1993), 1-17; John Clark, Modern Asian Art (Sydney: Craftsman House G+B Arts International, 1998); John Clark, Asian Modernities: Chinese and Thai Art Compared, 1980 to 1999 (Sydney: Power Publications, 2010).
} 
for local discourses to penetrate the non local'. Pursuing traditional methods and aims of art historiography, Clark's essay is a periodisation of the Asian Modern, which recognises particular modernities in Asian art by refocusing attention on the specific historical conditions in which modern Asian art develops. He draws on historical documents of art, especially artists' biographies and career training and their related artworks, in order to present paradigms or 'types' for a chronological but also taxonomical mapping of the Asian Modern. In particular, Clark offers 'five generational artistic cohorts' aligning with 'five rough periods': I Transitions to Modernity, 1850s-1890s; II Academy Realism, Salon Art and the National, 1880s-1910s; III Early Modernism, 1920s-1930s; IV Abstractionism and Conceptualism, 1940s-1960s; V The Contemporary, 1980s to the Present. By tracing and mapping key artists and artworks that fall into these divisions, Clark's essay is a significant contribution to the developing history of modern Asian art. Importantly, while Clark's essay draws our attention to the specificities of the Asian world, and a larger world of art history that must recognise the unique significance of modern Asian art to world currents, it is also concerned with how the Asian Modern comes into existence through the interplay of local and global connectivities, 'emplaced in a set of relations between domestic and overseas art centres'. Clark's work, in other words, also attends to how internal and external, or 'endogenous' and 'exogenous', currents are mutually constitutive in forming the Asian Modern and points to the particular kinds of connectivities that are shaped through these contingent relations.

Essays by Clark and Flores reflect on the seemingly contradictory processes of cultural differentiation and relativisation that are often features of worlding and world-making projects. They both, however, also shift away from these conventional antinomies and, rather, encourage a recognition of their mutual connectivity as integral to the figuring of Asian art. As Clark offers, "“Worlding" is a notion which implies a coherence other than that provided by internal discourses: it posits an outside, and this depends on how the nature and extent of the outside were reciprocally conceived'. Both essays also foreground the influence of colonialism in 'worlding' Asia and this, as Clark argues, 'In a sense, $[\ldots]$ is counterintuitive to a simple view of colonial processes as the imposition of a hegemony, rather than the collaboration with it. Such access had, at least theoretically, to include kinds of articulation of the local into the non local and vice versa'.

Similar to Clark's aims, Flores' essay is concerned with Asia-based worlding practices, but distinct from Clark's wider Asian purview, Flores focuses on the specific case of the Philippines. He uses the example of Philippine-based worlding as a 'dissent to dominant worlding' - that is, to that which casts EuroAmerica as the hegemonic position for viewing the world - and, rather, argues the case for worlding from the specific agency of the Philippine. Flores' essay 
also explores key figures in literature, film, music and theatre that illuminate Philippine experience and, in doing so, he articulates an archetypal figurethe 'polytropic Philippine' - as a legacy of a particular kind of worlding, drawn from Philippine-based experience and visions of the world. Through his examples of the national hero José Rizal, the singer Lea Salonga, the videoscapes of contemporary artist Stephanie Syjuco, and the Filipino domestic workers pictured in the Hong Kong interiors in which they work in photographs by Chinese artists Sun Yuan and Peng Yu, Flores argues the agency of the Philippine - that is, the 'Philippine remaking itself from a colonial object to a subjectivity that comprehends back'.

In particular Flores articulates a 'polytropic' condition that characterises the specific kinds of worlding enacted by these historical and contemporary Philippine cosmopolitans. He figures the life and thinking of Rizal, the Philippines' revolutionary national hero, as a key trope, but significantly, Flores casts the figure of Rizal more precisely as an emblematic 'polytrope' for the Philippine nation. He suggests the present-day veneration of Rizal as national hero is not merely a reflection of localised Philippine conditions of nationalism, but signifies the particular cosmopolitan sensibilities and aspirations of the Philippine national subject: their need to be 'compared with others' in order to gauge a 'sense of belonging to the world'.

Flores's piece eloquently argues that Philippine subjecthood is always in intimate relation to the larger world. Like the archipelago, it is in some ways deterritorialised-such as the splitting of and into the archipelago-but connected nonetheless. The 'identification, identity and imitation [of the Philippine] are instances of intimacy' that connect the Philippine with the world. ${ }^{7}$ Thus, the Philippine is a manifestation, or more precisely, personification of the connectivity which lies in-between worlds, that interconnecting the local and non local, or outside and inside, and which 'mediat[es] discrepant worlds'. As with Clark's essay, Flores at once probes the boundaries and complex relations of the exogenous and endogenous. The polytropic Philippine is thus cast as a national subject whose experience is underlined by a complexity of both local and global connections, entanglements and affiliations.

7 Patrick Flores, abstract for keynote paper 'The Philippine Polytrope: Intimating the World in Pieces' presented at 'The World and World-Making in Art' conference, Humanities Research Centre, The Australian National University, Canberra, August, 2011. 


\section{Contemporary Art's Affective Impulse: Relating and Responding to Contemporary Asian Art}

Essays by Flores, Meskimmon and Maravillas especially, register art's affective and sensory possibilities to bridge borders of cultural difference and point to issues of common, if differently situated, human experience in the world. Flores points to shared experiences of 'loss' that are empathetically felt and performed in the daily lives of Philippine people, whether at home in the Philippines or as part of Philippine diasporic experience:

the polytropic Philippine is temporary, alien or exile, guest worker or second family, surrogate mother or housekeeper, first teacher or mail order bride, plural in its sympathies, assuming the grief of others and suffering its own, moving - mobile and heart wrenching, modern and melodramatic - and compassionate in many ways, that is, suffering together with passion.

Thus, Flores's essay reminds us of the real and life-sustaining co-dependencies of the Philippine and/in/of the world, as registered in the labour of the Philippine overseas contract worker (OCW) population that live beyond the nation's borders to sustain the nation's livelihood. It is more clearly via Flores's account of the affective connectivity demonstrated by a Philippine singer's rendition of the classic jazz standard Autumn Leaves, however, that his essay ties with the newly theorised concerns of affective response to contemporary art and which connects to other essays in the volume on this theme. As Flores argues, the lack of an autumnal season in the Philippines is no obstacle to a young Philippine singer's stunning rendition of (or in Meskimmon's terms, 'response to') a recognisably American anthem. Rather, the feeling of loss that is central to the lyric and mood of the song is harnessed by the singer as a means of connecting with the spirit of the song, and to have others respond or connect to it, through their own experiences of loss and suffering.

Likewise, Meskimmon explores themes of loss and suffering through the empathetic and sensory relation engendered through art and turns to specific instances of this in the contemporary practice of artists Dadang Christanto and Araya Rasdjarmrearnsook. Christanto, originally from Indonesia, has been resident in Australia since 1999; Rasdjarmrearnsook is a Thai woman artist. Both have made significant contributions to contemporary Asian art, ${ }^{8}$ especially through their moving performance and installation works, and might be further framed within a 'South-East Asian' regional imaginary of

8 Even within Australia, Christanto is still largely framed as an Indonesian artist in the collections and exhibitions of major Australian cultural institutions. 
contemporary art. ${ }^{9}$ While Meskimmon's exploration of these artists' practice recognises their particular Asia-based experiences and concerns, the kinds of connectivity she explores are not limited by geographical or cultural horizons. In fact, Meskimmon articulates an argument about the affective capacity of contemporary art to allow empathetic and sensory connections between people across cultural, linguistic and social borders - to allow 'a place in which we can imagine and respond to other people who are different from ourselves'.

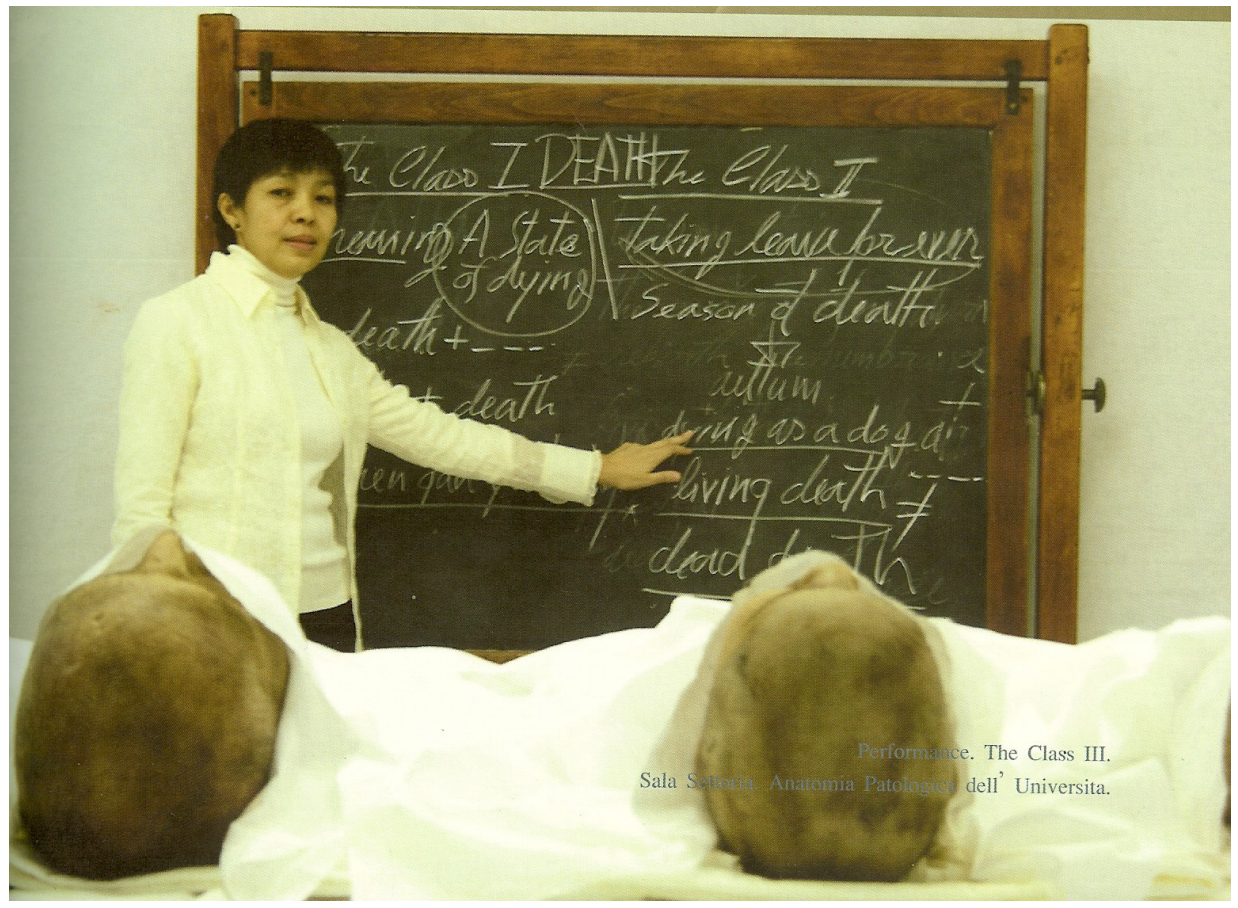

Araya Rasdjarmrearnsook, The Class III 2005; video installation; 16.25 min.

Work and image courtesy: Araya Rasdjarmrearnsook, with kind assistance of 100 Tonson Gallery, Bangkok

Such a space, Meskimmon suggests, is meaningful to generating a 'cosmopolitics of response' that is suggestive of both senses of 'responding to' art: that is, through the literal, sensorial reaction to art, but also the kinds of ethicopolitical 'answering to' that projects such as those offered by Christanto and Rasdjarmrearnsook elicit in their ability to 'touch' and 'move' others affectively and even to provoke them into political action or responsibility for fellow human beings. This kind of cosmo-politics of response also subsequently

9 T.K. Sabapathy, 'Developing Regionalist Perspectives in South-East Asian Art Historiography', in The Second Asia-Pacific Triennial of Contemporary Art (Brisbane: Queensland Art Gallery, 1996) 13-17; Iola Lenzi, ed., Negotiating Home, History and Nation: Two Decades of Contemporary Art in Southeast Asia 1991-2011 (Singapore Art Museum, 2011); Antoinette, Reworlding Art History. 
assists in the generation of a 'cosmopolitan imagination' that Meskimmon has articulated elsewhere, ${ }^{10}$ a " "cosmopolitan" mode of responsibility, in which subjects simultaneously acknowledge the difference and specificity of others' experiences, yet respond generously to them'. In her essay, Meskimmon engenders connectivities via these dual meanings of response and the kinds of ethico-political responsibilities they invoke. Through this, she also shows how Christanto and Rasdjarmrearnsook 'connect the micro-stories of individuals with the macro-histories of global geopolitics ...' through what she describes as a form of 'unbidden giving'. Thus, we might trace the obligation to respond, to give, and to impel a further giving, as yet another narrative and praxis of connectivity in the art production-reception process which draws the subject of art, the subject of the artist, and the subject of the audience-participant into webs of intersubjective relation.

Subjectivity itself, as Meskimmon reminds us, 'emerges in and through its fundamental interconnectedness with others'. Christanto and Rasdjarmrearnsook's projects are argued to 'have crossed worlds, eloquently articulating local, Asian experiences of loss, mourning and reclamation while, at the same time, communicating fluently with global audiences,' revealing particular Asian stories and their larger resonance in the world. They therefore give rise to a different platform for world-making, from Asian-led perspectives that are also situated within a 'cosmo-politics' of 'transnational, transcultural generosity'. ${ }^{11}$ Importantly, Meskimmon highlights the audience encounter with art as central to the production of art's meaning. As she argues, the art of Christanto and Rasdjarmrearnsook finally depends on the audience-participants' own sense of connection to the feelings of loss and suffering expressed and elicited through their respective art projects. For their art is not didactic in its communicative intent and call to response, but rather elicits audience response via art's affective or sensory invitation to empathic relation and dialogue with others.

Indeed, connectivities also evoke the concept of 'relation' - including 'relating to' and 'relating with', and the kinds of relationships drawn by and through art. This is central to a new stream of contemporary art theory and practice which engages artists and their publics in conscious relation with each other, variously described and debated as 'relational', 'socially engaged', 'community-engaged' and/or 'participatory' art. ${ }^{12}$ This may be contrasted with modern notions of

10 Meskimmon, Contemporary Art.

11 Marsha Meskimmon, essay abstract for this book: 'Response and Responsibility: On the Cosmo-politics of Generosity in Contemporary Asian Art'.

12 See the key art historical work undertaken, for example, by Nicolas Bourriaud, Relational Aesthetics (Dijon: Les Presses du réel, 2002; Esthétique relationnelle 1998). Claire Bishop, AAntagonism and Relational Aesthetics', October (Fall 2004, No. 110): 51-79. Grant Kester, Conversation Pieces: Community and Communication in Modern Art (Berkeley and Los Angeles: University of California Press, 2004). 
the artist as individual genius, whose art is firmly framed as an autonomous product of individual authorship. Several essays draw attention to these kinds of socially connected art practice and the ways in which they resituate the conventional roles of and relations between art, artist, and audience and, in turn, generate alternative meanings about the role and value of art itself. They reflect the recent positioning of contemporary art, not merely as a signifier or mirror of the world, but as a form of relational process, collaboration and/or engagement. In this, acts or modes of connection and connectivity may be read as essential to the 'relational' process, namely between artists, their audienceparticipants, and the resulting 'art' they produce in collaborative and/or participatory engagement with each other. They suggest that such engagements are not necessarily smooth, harmonious or seductive connections, but can also be a field of political contestations, transgression and trespassing, where the limits to the autonomy of the artist and audience-participant or 'guest' and 'host' are tested and traversed.

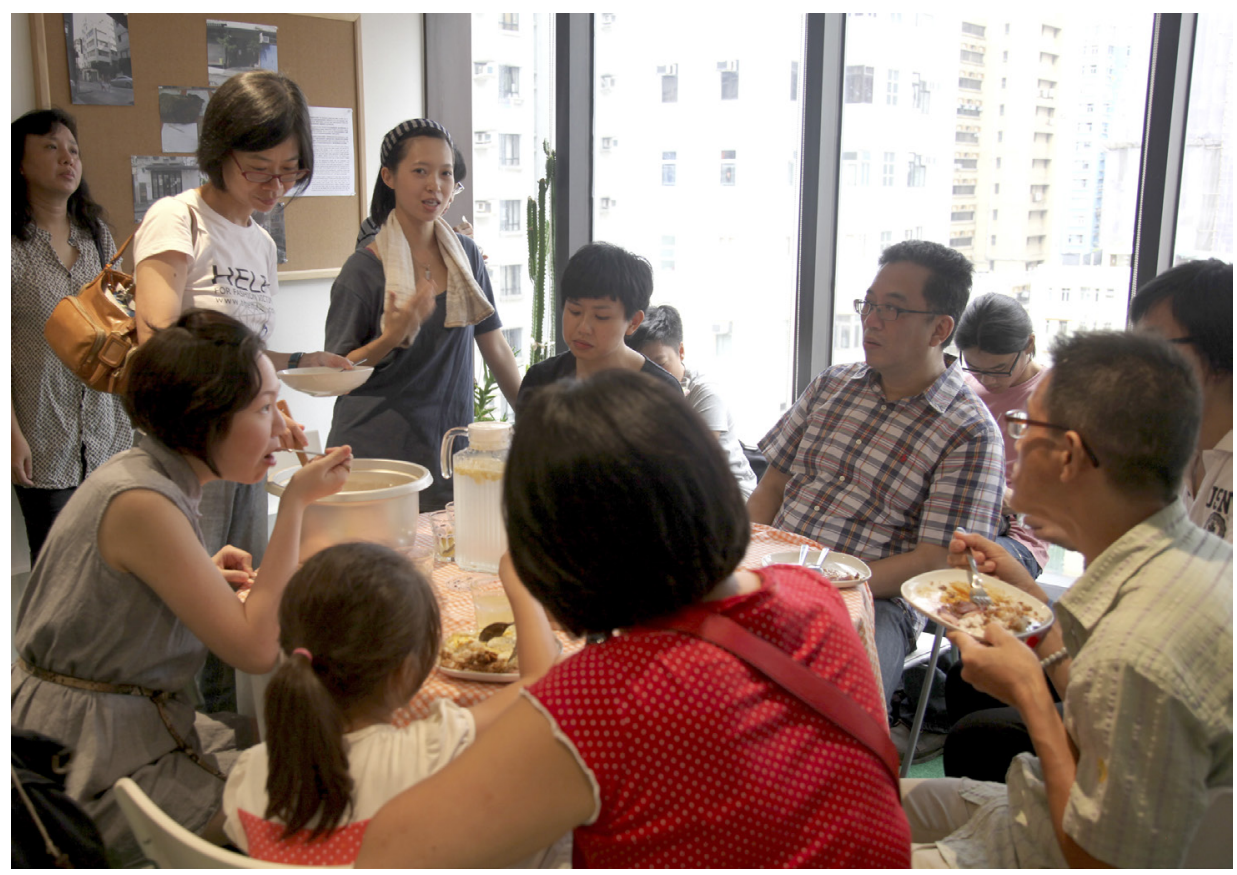

\section{Asia Art Archive Open Weekend 2013. Spark! Programme MEALS \&} SHARING 'Art Tastes Salty', 7 July 2013.

Image courtesy Asia Art Archive

Like Meskimmon, Maravillas's essay highlights the intersubjective relations which are foregrounded in forms of contemporary art practice, underscored by an ethics of 'giving' and 'receiving'. Maravillas's essay, however, is especially 
concerned with the new kinds of relational art practices engaged in aesthetic acts of hospitality, specifically through food-based 'alimentary' art projects. Situating his reflections within a triangular field of recent theory - 'relational aesthetics', 'cosmopolitanism', and 'hospitality' - Maravillas explores how contemporary Asian art might suggest 'alternative and more extensively relational frameworks for understanding home and hospitality' through the making of affective and sensuous worlds across difference. Exploring the shared subject matter of 'food' as a connective thread in various projects of contemporary Asian artists, particularly Rirkrit Tiravanija, Mella Jaarsma, Lee Mingwei, and Roslisham Ismail (aka Ise), Maravillas examines the relational dynamics of artistic projects that invite audience-participants to participate in exchanges of hospitalitythat is, 'giving to' and 'receiving from' others.

In particular, Maravillas explores the ethico-political import and sensuous connectivity of these performance-based art practices, including the larger 'transnational and diasporic vectors of connection to an imagined "home"' in which they are enmeshed. He considers the value of cosmopolitan frameworks for reconfiguring notions of home, belonging and community in a region marked by the legacy of multiple colonial and postcolonial histories. Significantly, he argues that the 'performative, relational and sensuous processes of the alimentary ... sets the table and the stage for the enactment of an artful hospitality and connectivity through generous and responsible acts of "worldmaking"'. Culturally situated practices of alimentation and world-making, Maravillas contends, are crucial to these projects' particular translations (of hospitality, home and belonging) and their connective effect (across spaces and temporalities, for instance). While the art of Rirkrit Tiravanija has become among the most well-known in this genre due to its international attention in exhibitions by the French curator Nicolas Bourriaud, Maravillas describes a wider concern with food-centred art practices among Asian artists and argues the differentiated and situated meanings of performative, participatory or relational art practices with respect to specific audiences of reception and the specific kinds of cultural translation each audience brings to interpretations of contemporary art by Asian artists.

\section{Intra-Asian Regional Connections: Art, Exhibitions, and Curating, on Asian Terms}

Another theme of this volume concerns intra-Asian regional dynamics that explore art-related connectivities within and across the otherwise discontinuous geographies of Asia. The essays addressing this theme recover the historical importance of regional connection across and within Asia and register the 
continuing importance of inter- and intra-regional links, especially after colonial separations and in view of new Asia-based art initiatives which (re-)connect the region in the twenty-first century. Essays which directly address intraregional connections include those by Chaitanya Sambrani, Oscar Ho, Charles Merewether, Turner, and myself.

Recent scholarship in Asian studies, and especially intra-Asian studies, reflects theories and models of connectivity that are premised on intra-regional or 'intra-Asian' relations; these may be compared with other types of connective cultural work premised on other kinds of prefix, including 'the inter-cultural', the 'cross-cultural', and the 'trans-cultural'. As with processes of worlding and world-making, for intra-regional practices there is a basis of comparative relation based on difference, but also similitudes of socio-historical and political experience. The emphasis rests on adjacencies and networks of relation across Asia itself. ${ }^{13}$ Often this work seeks to uphold Asia not only as an important subject of study, but attempts to recover localised tools and methods for studying Asia comparatively across the region so as to avoid hegemonic Euro-American methodologies and perspectives. ${ }^{14}$ The work of recovering and inscribing art histories for the region as the consequence of their specific and situated contexts, may be understood in this vein.

Perhaps one of the most obvious means of new intra-regional connection is via the web-based digital technologies or ICTs (information and communication technologies), which emerged in the late twentieth century and created new channels of communication between diverse Asian societies and between Asia and the rest of the world. Web-based technologies permit day-to-day communications between neighbours in the region that were previously separated by borders of space, time, languages, history and colonialisms. ${ }^{15}$ Furthermore, apropos of contemporary art itself, new digital and 'web art' forms have also been instrumental to the development of cross-cultural collaborative or exchange-based art projects which actively seek to creatively connect with distant others in ways that were previously restrained by physical distance. Artist groups such as Raqs Media Collective (India), tsunamii.net (Singapore), Young-Hae Chang Heavy Industries (South Korea), and House of Natural Fibre (HONF, Yogyakarta) are among those that have harnessed the so-called 'new media' technologies often towards collaborative art practices. Operating since 1998, the Brisbane-based MAAP-Media Art Asia Pacific, also mentioned in

13 See Chen Kuan-Hsing, with Kuo Hsiu-Ling, Hans Hang \& Hsu Ming-Chu, eds, Trajectories: InterAsia Cultural Studies (London: Routledge, 1998). See also Chen Kuan-Hsing, Asia as Method: Towards Deimperialization (Durham: Duke University Press, 2010) and Chen Kuan-Hsing \& Chua Beng Huat, The InterAsia Cultural Studies Reader (Abingdon: Routledge, 2007).

14 Chen, Asia as Method.

15 S.Y. Chia \& J.J. Lim, 'Singapore: A Regional Hub in ICT', in Towards a Knowledge-based Economy: East Asia's Changing Industrial Geography, eds S. Masuyama \& D. Vanderbrink (Singapore: Institute of Southeast Asia Studies, 2003), 259-98. 
Turner's essay, was established 'to bring focus to "unmapped" media art activity from Australia, Asia and the Pacific. ${ }^{16}$ Initiatives such as MAAP have brought to light the strength of new digital art forms across many parts of Asia, especially as these forms have become increasingly inexpensive and accessible in societies that have limited public infrastructure and resources to foster art or lack the physical space for traditional art studios.

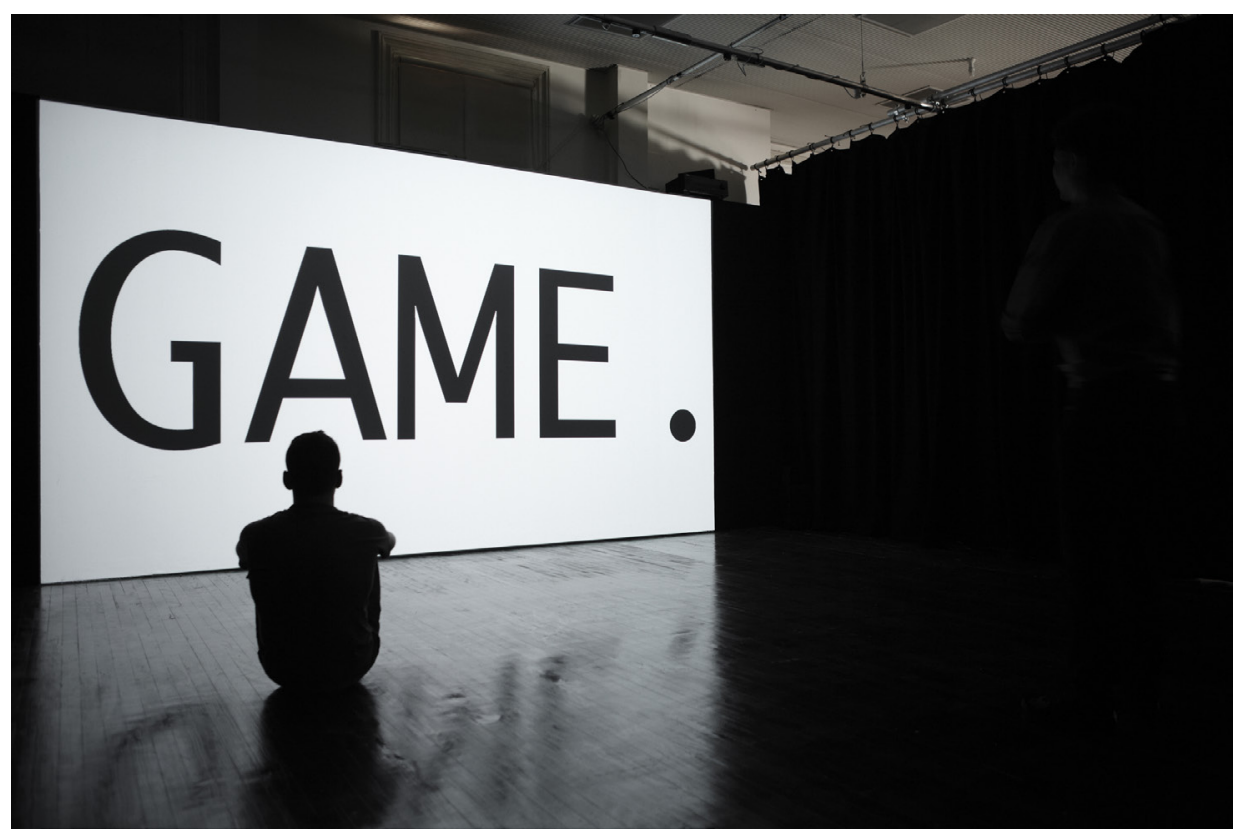

YOUNG-HAE CHANG HEAVY INDUSTRIES, YOUNG-HAE CHANG HEAVY INDUSTRIES, THE SLICKEST LITTLE KOREAN SCUMBAG DOWN UNDER (2012); original text and music soundtrack; HD QuickTime movie. Commissioned by Campbelltown Arts Centre and 4A Centre for Contemporary Asian Art for Edge of Elsewhere 2012.

Courtesy the artist; photograph: Zan Wimberley; image courtesy 4A Centre for Contemporary Asian Art

If 'new media' contemporary art forms offer new types of creative connection, as in the past, artists continue to demonstrate the concerns of their age via shared subject matter. In this volume, Merewether looks to the shared subject matter of Asia's 'seas' as a connective thread across instances of contemporary Asian art, tracing contemporary artists' common concerns with Asia's rapid industrialisation and urbanisation from the late twentieth century, and their effect for Asia's landscapes and territories. As Merewether suggests, artists are highlighting the pressing issue of Asia's changing natural environments and the socio-political consequences of this for Asia's present and its futures.

16 See MAAP-Media Art Asia Pacific, accessed 16 October 2013, http://www.maap.org.au/about-maap/. 
This is obviously not only of increasing regional concern, but a matter of significant world interest in view of global climate change. Beyond subject matter, Merewether also considers the aesthetic connections of contemporary Asian artists who engage with Conceptual art, not merely their links to international art movements but also to their Asian Conceptual art predecessors of the 1960s and 1970s. Thus, Merewether captures multiple intra-Asian currents with effect for the region: the subject matter of art, art movements and histories, and sociopolitical matters of regional relevance. Moreover, his multi-sited art historical mapping and method, across different parts of Asia, allows us to view intraAsian maps with 'up close' specificity at the same time as 'zooming out' to trace broader lines of artistic sharedness and socio-political interconnectivity across the Asian region, and beyond. As Merewether's essay highlights, the art of a particular generation often brings into relief the most urgent concerns affecting societies - in this case, how Asia's natural environments have undergone dramatic change and, in matters of governance, how Asia's territories are literally being reshaped and rezoned through land reclamations and urban projects, remaking the reality of Asian worlds for the present and the future.

Exhibitions and their curatorial motivations are also flagged as an important space for developing intra-regional cross-cultural connections. Sambrani's essay, which focuses on his own 2010 exhibition, Place.Time.Play: Contemporary Art from the 'West Heavens' to the 'Middle Kingdom', suggests a renewal of intraAsian connections through contemporary art curatorship and exhibitions - in this case, between India and China within the larger frame of the 'West Heavens' project, also discussed by Turner. Initiated by Chinese art curator, academic and entrepreneur Johnson Chang (Chang Tsong-Zung), the 'West Heavens' project seeks to probe 'how contemporary Chinese artistic and academic cultures might benefit from interactions with their Indian counterparts', with the name of the project recalling 'the ancient Chinese name for India, as the heavenly realm lying to the west'. ${ }^{17}$ Reflecting on his own 'curatorial adventure' from the conceptualisation of the exhibition through to its final presentation in Shanghai, Sambrani offers a personal account of the development of an exhibition of contemporary Asian art from the perspective of the curator.

In particular, Sambrani's curatorial perspective directs a lens onto the complexities of conceiving and carrying out an Asia-focused, cross-cultural exhibition in a transnational context, highlighting how such projects may provide channels for forging new, intra-regional cultural connections in the twenty-first century, especially in the face of the politically complex relationship between India and China. At the project's outset Sambrani asks, 'For all their historical connections, what did contemporary artists from either country really

17 See the 'West Heavens' project website, accessed 6 October 2013, http://westheavens.net/en. 
know of each other's work?' ${ }^{18}$ Indeed, the 'West Heavens' project is significant in its status as the first intellectual and creative engagement across the art and academic cultures of India and China, with no substantial precedents for engagement between artist communities from these countries. As Sambrani has described, Place.Time.Play encouraged artists to use each other's countries as 'a laboratory in which to test new ideas for cross-cultural engagement'; artists were invited to engage in 'universal, yet locally situated, extensions of their current practice' and undertook reciprocal research trips in India and China as part of the exhibition development. ${ }^{19}$ Sambrani argues that this cross-cultural connectivity enabled 'a different vision of "global" or "international" art, one that is premised on encountering that which is at once deeply intimate and incontrovertibly foreign' ${ }^{20}$ Sambrani contrasts this with the frenzied and less critically engaged commercial transactions with contemporary Asian art, now common to the global art marketplace: the growth of new Indian and Chinese art markets in the two countries has brought economic attention to contemporary Chinese and Indian art but also contemporary Asian art more generally, and the result may sometimes be an economically driven spectacularisation of Asian art rather than a critical engagement with it. ${ }^{21}$ Importantly, Sambrani's project also reveals the obstacles and limits of cross-cultural/transnational projects and the difficulties of forging connectivities between cultures, even where there is the will to do so. As his essay points out, cultural institutions are also reflections of the unique socio-political, cultural and bureaucratic imperatives which underwrite them, and thus, may present hurdles for presenting contemporary art across cultures and connecting differently situated Asian societies. Nevertheless, as Sambrani's essay highlights, the key significance of Place.Time.Play and the overall 'West Heavens' project vision, is the reconfiguration of curatorial methods and exhibition models which bypass the need for Euro-American legitimation and rather attends to Asia-based experiences, and exhibitions on Asian terms.

Not unrelated to Sambrani's concerns, Hong Kong-based artist, curator and academic Ho offers a critique of hegemonic, Euro-American-influenced models of curatorship and argues their problematic effects for museum and exhibition development in Asia. Similar to Sambrani's efforts to avoid the hegemonic imaginary of a Euro-American audience for Place.Time.Play

18 Chaitanya Sambrani, essay proposal for this book: 'An Experiment in Connectivity: From the "West Heavens" to the "Middle Kingdom"".

19 Chaitanya Sambrani, 'When India and China Engage: A Curatorial Adventure', conference paper abstract for 'The World and World-Making in Art' conference, Humanities Research Centre, The Australian National University, Canberra, August, 2011.

20 Sambrani, 'When India and China Engage'.

21 Important new art fairs in Asia, which demonstrate the increasing commercial significance of Asian art, include the Hong Kong International Art Fair (Art HK) established in 2007 and superseded by Art Basel Hong Kong in 2013; and the India Art Fair (established in 2008 and formerly known as India Art Summit). 
and to instead position his exhibition for Chinese and Indian audiences, Ho contends that the kinds of curatorship required for developing exhibitions and, by extension, museums in Asia must be premised on a different set of culturally based considerations that relate specifically to Asian situations and local conditions. Thus, Ho argues, the experience of curating and exhibiting for Asian audiences within Asian contexts should be regarded as a contextspecific exercise that bears specific connection to Asia and should, therefore, be premised on a different set of conditions and histories than that inscribed in hegemonic Western-influenced exhibition models. Ho cites the development of the $\mathrm{M}+$ 'museum' project at Hong Kong's new West Kowloon Cultural District (WKCD) as a key case study; the long awaited $\mathrm{M}+$ cultural project forms part of the recent flurry of initiatives by the Hong Kong Government to develop the economic potential of cultural industries. Examining the particular conditions and necessities of cultural institutions in Asia, Ho argues ambitious projects such as M+ are seemingly always 'under the shadow' of invited Western experts who 'play a dominant role in shaping the content and the format of presentations' in Asian cultural institutions. This situation, Ho contends, is problematic for 'efforts to create a cultural landscape that is of distinctive local characteristics' and to develop 'cultural languages and operational models that are distinctively Asian'. ${ }^{22}$ Ho compares this with the work of independent or 'alternative' art spaces and initiatives and, more specifically, the curatorial work affiliated with such art projects, with their more experimental and locallyinformed models and methods. In 2011, with the support of the Asian Cultural Council Hong Kong, Ho set up the Asian Curatorial Network (ACN) to develop an intra-regional platform for dialogue between such independent Asia-based curators and spaces, so as to provide a forum for discussing their 'alternative' methods and particular challenges (i.e. political, bureaucratic, resource-based and infrastructural) for developing exhibitions in Asia and for Asians and to exchange ideas on how to achieve their successful implementation. As Ho hints, this concern to develop Asia-specific models of exhibition must necessarily be tied to the education and training of a new generation of Asia-based art professionals in order to meet the new demands of Asia's growth in the cultural sector. 


\section{Australia-Asia and 'Australia in the Asian Century'? ${ }^{23}$}

The final theme of the volume is Asian-Australian connections, which encompasses specific Australian concerns, especially Australia's continuing interest in cross-cultural, art-based partnerships with Asia (see Turner, Carroll, this volume). The essays reflecting this theme probe particular art-related collaborations and exchanges between Australia and Asia and intersect with the topic of the Australian Research Council (ARC) project by Turner and myself on Asian art networks. ${ }^{24}$ In varied ways, the essays explore Australia's cultural relationship with Asia now and historically and, to some degree, probe how Australia is perceived from within the Asian region and vice versa (see Lo, this volume).

This theme, which addresses specific connectivities between Australia and Asia, is especially motivated by questions about Australia's historical, present and future role with, and even, within Asia as part of an 'Asian' or 'Asia-Pacific' geo-cultural imaginary. Papers by Alison Carroll, Pat Hoffie and Jacqueline Lo, in particular, are situated within these historical and contemporary currents of Asia-Australia relations and elaborate on these issues. The white paper, Australia in the Asian Century, ${ }^{25}$ for a brief period spurred fervent discussion again regarding the establishment of new cultural initiatives between Australia and Asia, but as Turner argues and other contributors attest, it should not be forgotten that over the course of recent decades various cultural agencies have been and continue to be highly active in seeking to connect Australia with Asia and vice versa. Such projects are often positioned within the realm of cultural diplomacy; for instance, as also noted by Turner, Melbourne-based Asialink is steered by a mission 'to work with business, government, philanthropic and cultural partners to initiate and strengthen Australia Asia engagement.'26 Asialink Arts, discussed by Carroll, aims to 'develop opportunities for cultural exchange between Australia and Asia and improve the Asia capability of the cultural sector based on the principles of partnership, collaboration and reciprocity. ${ }^{27}$ Art-making and art exhibitions can be regarded as keys to forging new relationships with unfamiliar others, so as to relate 'Asian' experiences to 'Australians' and vice versa. Beyond the display and mirroring of culture, such projects are also spaces for the negotiation and translation of culture via the mutable text of art, with its openness to varied meanings across different

23 Department of the Prime Minister and Cabinet, Australia in the Asian Century, white paper (Canberra, 2012).

24 Caroline Turner \& Michelle Antoinette, 'The Rise of New Cultural Networks in Asia in the Twenty-First

Century', Australian Research Council project 2010-2013 (DP1096041).

25 Australia in the Asian Century.

26 Asialink, 'About Us', accessed 7 October 2013, http://asialink.unimelb.edu.au/about_us.

27 Asialink, 'Arts', accessed 7 October 7 2013, http://asialink.unimelb.edu.au/arts. 
cultural contexts of production and reception. Importantly, alongside the successes of such cross-cultural exchange projects are the significant lessons learnt from the challenges or difficulties in achieving intercultural engagement and connectivity. Arguably it is through instances of the so called 'failures' of such projects that productive acts of cultural translation and negotiation are often made possible.

Along with the Fukuoka Asian Art Museum, the recurrent Brisbane-based AsiaPacific Triennial of Contemporary Art (APT), also discussed by Turner, helped to enhance international knowledge of contemporary Asian and Pacific art at a time when there was little regard for contemporary art that was produced outside Europe and the United States. Established in 1993, the APT was preceded by other Australian initiatives to engage Asia - such as the Artists' Regional Exchange (1987-1999), ${ }^{28}$ and the Biennale of Sydney's sporadic inclusion of Asian artists since its inception in 1973. Unlike most biennales and triennales, the APT has carved a distinctively 'Asia-Pacific' regional focus and assisted in forging an international presence for contemporary 'Asian' and 'Pacific' art, even an 'Asia-Pacific' art.

Hoffie explores the APT's connection to current art historical debates being played out with regard to the definition and exhibition of 'contemporary art'. More precisely, she probes changing and contested notions of 'the contemporary' both as a category of art and a marker of temporality. By recalling the history of the APT, including the original exhibition motives of the first three triennials $(1993,1996,1999)$ and their means of negotiating the contemporary', Hoffie argues that the definition of contemporary Asian and Pacific art had changed by the time of the seventh triennial (2012-2013). To this end, Hoffie argues the necessarily interconnected currents of 'tradition' and 'change' as constituent parts of any understanding of 'the contemporary' and, therefore, influential factors in defining how such art should be presented within the space of the APT.

More specifically, Hoffie describes the inter-connectivity between 'tradition' and 'change' in terms of a 'collision' and 'morphing', whereby 'tradition', on the one hand, is 'associated with memory, history and place' and 'by implication ... with the past', and on the other, 'change' is 'associated with the here and now' and 'with the tempo of movement and the blur of shapeshifting'. Borrowing from the curator Natasha Conland, Hoffie argues that the disorderly inter-connectivity underlying contemporary art is a necessarily and productively 'irreverent' manifestation, 'an active, contested zone of conflict, contrapuntals, contradictions, productive confusions, contrarieties, contrasts'.

28 ARX was a biennial artist exchange project established in Perth, Australia, in 1987 involving 'Asia-Pacific' artists, including a sizeable number of South-East Asian artists. 
In so doing, Hoffie highlights another connection - that of contemporary Asian art to its particular socio-historical, geographical and cultural contexts, as well as the specific temporalities of its production. Moreover, she points to the creativity of indigenous Asian cultures, including via contemporary artists who bring indigenous concerns to their art practice, such as the late Filipino artists Santiago Bose and Roberto Villanueva. Such art, she argues, productively complicates established notions of 'contemporary' art, so that tradition does not necessarily signal cultural concerns of the past but lives on in active creative engagements situated in the present and future. Indeed, if the 'contemporary' is understood simply as a marker of time, then many indigenous cultures demand a reframing of the Western logic of linear time, and a dismantling of the history of art as a narrative of successive 'avant-gardes' - the ever-new which displaces the ongoing and living significance of tradition that is practiced in many nonWestern cultures. ${ }^{29}$

The Australian interest in Asia also partly reflects the situation of Asian diasporas in Australia and their ongoing generational effect in carving a space of AsianAustralian relations and Asian-Australian identity from within Australia. ${ }^{30}$ As essays by Lo and Turner highlight, the Australian engagement with Asia is not new; rather, it follows on from a longer history of relations between Australia and Asia, but also Asian-Australian relations within Australia. In the area of art, key pivots for revisiting what is meant by Australian art were propelled by indigenous concerns, multicultural issues and the rise of republican sentiments in the 1990s. With regard to Asian-Australian creative interventions, as discussed by both Lo and myself (Epilogue), significant density was gained around the group of Asian-Australian multidisciplinary artists (including John Young, see Lo), who formed their own collective, 4A (the Asian Australian Artists' Association)-'a non-profit organisation established in 1996 to present and promote the work of Asian and Asian-Australian artists' ${ }^{31}$ Alongside this has been a growing scholarship on Asian-Australian studies, especially that supported by the work

29 See Nicholas Thomas, 'Our History is Written in our Mats: Reflections on Contemporary Art, Globalisation and History', The 5th Asia-Pacific Triennial of Contemporary Art (Brisbane: Queensland Art Gallery, 2006) 24-31; Nicholas Thomas, 'Contemporary Art and the Limits of Globalisation', in The Second Asia-Pacific Triennial of Contemporary Art, eds Caroline Turner and Rhana Devenport (Brisbane: Queensland Art Gallery, 1996), 17-18.

30 This is not unlike the work undertaken to explore the cultural experiences of Asian diasporas in other societies, such as in the United States. See Jacqueline Lo, Dean Chan \& Tseen Khoo, 'Introduction-Asian Australia and Asian America: Making Transnational Connections', Amerasia Journal 36, no. 2 (2010): xii-xxvii. 31 Previous affiliates of 4A include former directors Melissa Chiu (founding director) and Binghui Huangfu. Early members include: John Young, Vicente Butron, Chris Pang, Kim Moore, Philip O'Toole, Felicia Kan, Victoria Lobregat, Emil Goh, David Lui, Kate Mizrahi, Dacchi Dang, Lindy Lee, Guan Wei, Melissa Chiu, Laurens Tan, Cindy Pan, Hari Ho, Su-Lin Tse and My Lee Thi. See http://www.4a.com.au/about-4a/ (accessed October 8, 2013). 
of the Asian-Australian Studies Research network (of which Lo is Chair), which includes research clusters focusing on visual culture, performing arts, and literature, among other Asian-Australian cultural practices. ${ }^{32}$

As Lo's essay highlights with reference to the recent art practice of AsianAustralian artists, Asia is not only 'out there', but also an already existing part of Australia's cultural fabric. These dual conditions, Lo argues, should be important considerations for Australia in its efforts to establish new narratives for engaging with Asia in the twenty-first century. Lo discusses the two artists John Young and Jason Wing in order to draw out their differently situated Asian-Australian positions, not only with effect for notions of their belonging to and in Australia, but also, belonging to and in the world. As Lo highlights, artists such as Young not only point to immediate Australian concerns but also historical issues of global resonance. From the vantage point of a diaspora artist, Young brings a transnational approach to otherwise nationally-defined histories, seeking to 'reawaken an intrinsic ethical impulse' in his audiences everywhere (and thus, corresponding with the artistic projects of Christanto and Rasdjarmrearnsook as discussed by Meskimmon in this volume). On the other hand, Lo also asks us to recognise the Asia already within Australia via the art practice of Jason Wing, whose art draws attention to the present-day legacy of historical cultural crossings between Aboriginal and Asian people, a critical and complex hybridity too often made invisible by hegemonic cultural narratives which seek to simplify, even obscure, the Asianness that is already within Australia. As Lo summarises for both artists: 'The works of Asian-Australians, such as Wing and Young, point to more nuanced ways of engaging with the complexities of Asia "out there", but also the ways in which an understanding of "Asia within" can enrich our understanding of who we are as a nation, and how we can relate in more meaningful ways with our near-neighbours.'

In the final essay in the book, the Epilogue entitled 'My Future is Not a Dream': Shifting Worlds of Contemporary Asian Art and Exhibitions', I discuss the work of a number of contemporary artists within the context of developments in contemporary Asian art over the last two decades. I return to a number of key themes raised throughout the essays in this book including the international exhibition of contemporary Asian art; new Asian art markets and cultural industries; the significance of independent art practices and curatorship in Asia in attending to local contexts; and contemporary Asian art which connects and responds to world issues. In particular, I reflect on the artwork of Liew Kung Yu, Phuan Thai Meng, Chen Quilin, FX Harsono, Wong Hoy Cheong, N.S. Harsha, Pak Sheung Chuen and Cao Fei, among others. Intersecting with the concerns of the authors represented in this volume, I consider artists' changed concerns in the twenty-first century, coinciding with shifts in Asia itself, new generations 
of artists and art-making, and transforming currents of contemporary Asian art practice, exhibition and historicisation. Through its engagement with Asia's pasts, contemporary Asian art, as this volume attests, is also deeply concerned with the present as a means for considering Asia's futures and, moreover, the world's futures.

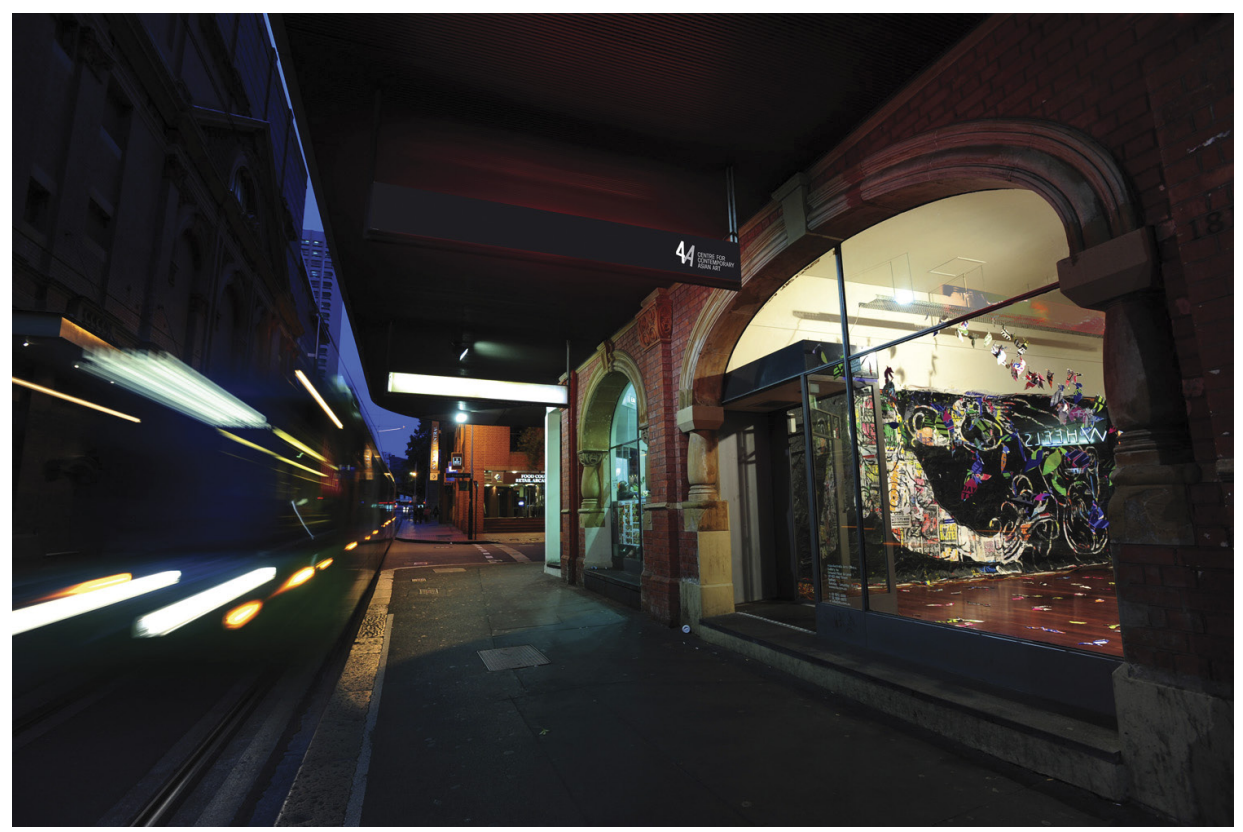

Exterior of 4A Centre for Contemporary Asian Art, Sydney.

Image courtesy 4A Centre for Contemporary Asian Art

\section{Asian Difference and Connection in the World}

Ultimately, we propose that the essays gathered here collectively ask, 'how might we think "difference" and "connection" in regard to Asia? And, in particular, the difference and connection that is inherent to modern and contemporary Asian art?' Indeed, these questions might serve as framing devices for thinking through contemporary Asian art, as readers encounter the various essays in this collection. While these are challenging questions, the essays here may be seen as efforts to examine such issues, to explore the complexities of these positionalities and their entanglements through views of the world from Asian and/or non Euro-Americentric perspectives, via empathetic and sensory engagements, across intra-regional currents of Asia itself, and in deepening diasporic and transnational networks, such as that connecting Australia and Asia. The essays not only expand our awareness of modern and contemporary 
Asian art as spaces of already existing commonalities and connection, but also suggest the ongoing activity of connecting across Asia and with Asia as a project of plural and ongoing possibilities that highlight renewed forms of regional and global cultural collaboration, exchange and crossings. They emphasise Asia's diverse, ever-changing and contingent cultural landscapes and the resonant affinities, resemblances and similitudes of Asian art with other conditions and experience in the world. They also suggest specific Asian histories and contexts for modern and contemporary Asian art and exhibition, illuminating distinctive trajectories of development and passages for the future.

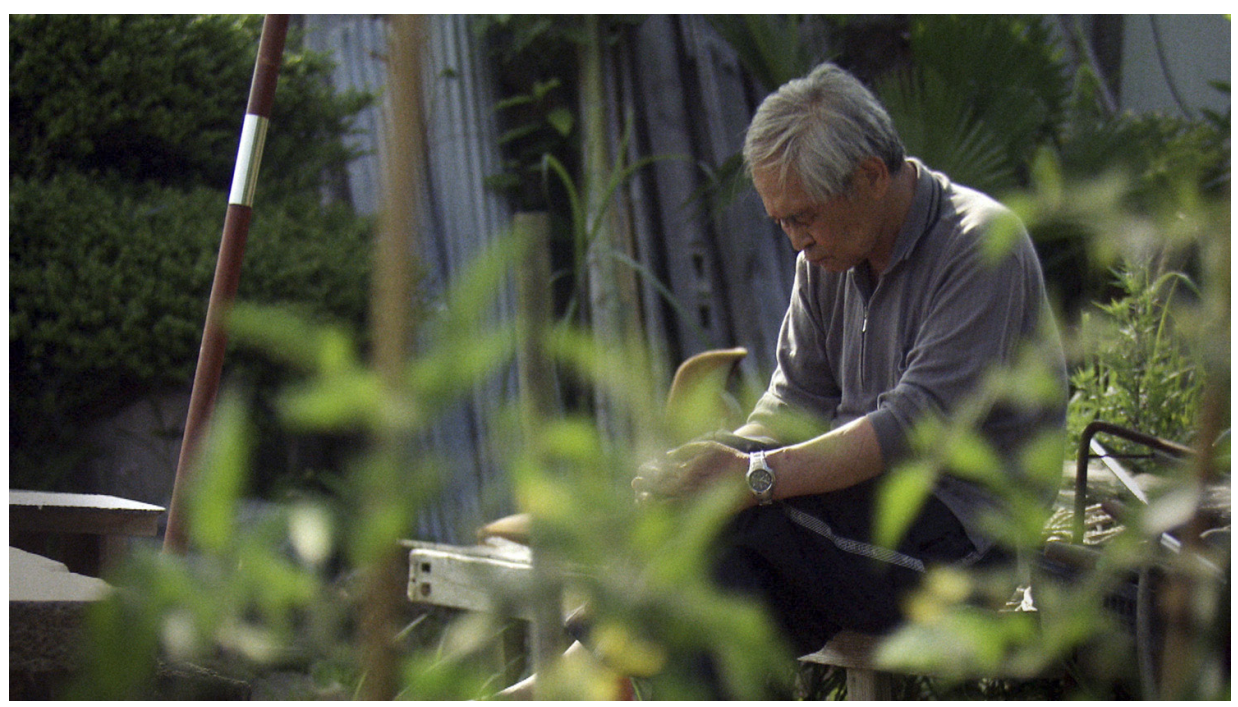

Fiona Tan, Indonesia/ Netherlands b. 1966, Cloud Island 2010 (still); HD installation.

Courtesy the artist, Frith Street Gallery, London and Wako Works of Art, Tokyo 
This text taken from Contemporary Asian Art and Exhibitions: Connectivities and world-making, by Michelle Antoinette and Caroline Turner, published 2014 by ANU Press, The Australian National University, Canberra, Australia. 